\title{
The Impact of Management Accounting Research: An Analysis of the Past and a Look at the Future
}

\author{
Marco Gatti \\ ${ }^{1}$ Department of Management, Università Politecnica delle Marche, Ancona, Italy \\ Correspondence: Marco Gatti, Department of Management, Università Politecnica delle Marche, Piazzale R. \\ Martelli 8, 60121 Ancona (An), Italy. E-mail: m.gatti@univpm.it
}

Received: February 4, 2018

Accepted: March 9, 2018

Online Published: April 18, 2018

doi:10.5539/ijbm.v13n5p47

URL: https://doi.org/10.5539/ijbm.v13n5p47

\begin{abstract}
This paper aims to explore the impact of management accounting research through a review of the literature on the issues related to this topic; some new avenues of research are also identified. In so doing, the paper contributes to both theory and praxis. In fact, suggesting new areas of research it promotes research in this field which, up to now, has been mainly focused on the determinants of the loss of impact rather than on the nature of the impact of management accounting research and its assessment. Moreover, this work aims to stimulate new research focused on tools and methods for measuring the impact of management accounting research; such tools can be useful to funding institutions and evaluation agencies which can be better equipped to carry out an ex-ante and an ex-post evaluation of the impact that management accounting research projects can have on society.
\end{abstract}

Keywords: research impact, research relevance, management accounting, literature review

\section{Introduction}

In recent years, the debate on the relevance of scientific research has grown significantly (Donovan, 2011; Holbrook \& Frodeman, 2011; Morton, 2015; Nicolai \& Seidl, 2010; Penfield, Baker, Scoble, \& Wykes, 2014; Reale, Nedeva, Duncan, \& Primeri, 2014). Academics are under pressure as they are ever more frequently called to demonstrate the impact that their research can have on society. This pressure stems from the fact that funding institutions, as well as governments, need to justify the assignment of resources to scientific research, showing how the latter can actually contribute to improving the economic, cultural, social, and environmental conditions of a community or of a country (Donovan, 2008). Moreover, given that resources devoted to scientific research are limited, there is also the need to utilise them to their fullest potential in order to maximise the returns to society. In this perspective, academics are called to prove the potential impact of their research in order to increase their chances of being funded.

In light of this, scholars have started to debate the relevance of their research in various and different disciplines (de Jong, Barker, Cox, Sveinsdottir, \& Van den Besselaar, 2014; Hammerfelt, 2014; Holbrook, 2010; Mostert, Ellenbroek, Meijer, van Ark, \& Klasen, 2010; Paolini \& Quagli, 2013; Quagli, Avallone, \& Ramassa, 2016; Tucker \& Parker, 2014). In some cases, the debate on relevance is still at an initial stage and it is mainly focused on what determines its achievement or, on the contrary, on the underlying causes of its loss, in an attempt to find solutions aimed to increase the relevance of scientific research. In other cases, the debate has evolved, leading to the design of methods aimed to ensure a reliable assessment of the impact that scientific research can have on society. This is the case for studies in the field of medicine which have advanced very quickly towards the elaboration of models, such as the Payback Framework, the Canadian Academy of Health Science Impact Framework, or the Economic Value of Medical Research, that aim to provide a reliable assessment of the impact of scientific research (Banzi, Moja, Pistotti, Facchini, \& Liberati, 2011; Buxton \& Hanney, 1994, 1996, 1998; Donovan and Hanney, 2011; Frank \& Nason, 2009; Murphy \& Topel, 2003).

The fact that academic disciplines have progressed toward different stages along that arduous process which leads to the measurement of the impact of scientific research should not be understood as a "delay" of some with respect to others. Rather, it is the consequence of their main distinctive features which can deeply impact the process of problematizing the relevance of scientific research. When scientific research deals with societal issues, that is, when there is a strong link between the object of research and a perceived need of society or, broadly 
speaking, a societal issue, the abovementioned problematisation process is activated very quickly and it is mainly directed towards the development of measurement systems able to ensure a reliable assessment of the impact of research. This is due to the fact that the closeness of the link between the object of research and its usefulness for society is explicit; that is to say, it does not need to be debated and it is often a taken-for-granted assumption. In other words, the usefulness does not "deserve" to be demonstrated; rather, it should be quantified.

On the contrary, academic disciplines like Social Sciences and Humanities, for example, in which the link between the object of research and a perceived need of society is not explicit, display a preliminary need to demonstrate that an impact can exist or to reflect on the causes for which an impact does not manifest itself. As a consequence, the problematisation process concerning how to assess impact represents a subsequent stage which can be reached if the existence of an impact has been already demonstrated, communicated, and acknowledged.

This paper focuses on the impact of management accounting research. In particular, it aims to analyse how studies in the field of management accounting have progressed, up to now, with regard to the issue at stake and, at the same time, to suggest some possible avenues which could inform future research. On the one hand, the paper strives to contribute to existing literature by systematising what has already been studied with regard to impact. On the other hand, it aims to stimulate reflections on how to enhance further research that could lead to narrowing the gap with other disciplines in which studies on the impact of scientific research have achieved a higher level of advancement.

The paper is organised as follows. The second section will introduce the concept of impact by discussing reasons for which it is relevant to study it and by analysing how it has been interpreted by existing literature. The third section analyses the state-of-the-art with regard to the impact of management accounting research. In particular, it aims to provide a broad overview of studies conducted and to systematise what has already been published in specialised literature. The fourth section suggests some avenues which could inform future research in the field of management accounting and, lastly, the fifth provides some concluding remarks.

\section{The Impact of Research: Origins and Meanings}

The growing interest in the impact of scientific research finds its roots in both theory and praxis. With regard to theory, scholars in different fields of research are ever more frequently acknowledging that a gap between theory and practice exists and that it has been expanding over time (Kieser \& Leiser, 2009; Mc Cown, 2001; Scapens, 2006; Upton, 1999; Wandersman et al., 2008). This, and the consequent risk that this gap could jeopardise the impact of scientific research, has attracted the attention of a large number of scholars who have undertaken to analyse the causes underlying its loss of relevance and the solutions which could be adopted to limit it. At the same time, several specialised journals, e.g. Research Evaluation or Scientometrics, have contributed to fostering the academic debate on the issue, showing that it represents a real "hot topic" for its concrete implications on society as a whole.

In addition to the interest originating from theory and stimulated by researchers and academic journals, it should be recognised that praxis has played a pivotal role in activating and carrying the debate on the impact of research. In particular, research-funding institutions more and more frequently ask for methods that can ensure a reliable assessment of the impact of scientific research, in an attempt to demonstrate the effects, in terms of public value creation, of their funding decisions and to inform their future funding policies. In line with this, the European Union has launched and funded several research projects which are focused on the design of useful methods for assessing the impact of scientific research. Among the most relevant, the IMPACT-EV project (Note 1) (Evaluating the Impact and Outcomes of EU SSH Research), begun in January 2014 and completed in December 2017, was designed to develop a permanent system of selection, monitoring, and evaluation of the various impacts of research in the Social Sciences and the Humanities. Similarly, the SIMPATIC project (Note 2) (Social Impact Policy Analysis of Technological Innovation Challenges), which started in March 2012 and ended in February 2015, aimed to provide policy makers with a comprehensive and operational tool box that would allow for a better assessment of the impact of research and innovation policies in Europe. Another example is the SIAMPI project (Note 3) (Social Impact Assessment Methods for research and funding instruments through the study of Productive Interactions between science and society) which started in 2009 and ended in 2011. The basic assumption underlying SIAMPI was that research is impactful if it is the result of a productive interaction between science and society. In this perspective, its assessment should entail the analysis of the relationships, and the measurement of their intensity, that researchers establish with stakeholders in an attempt to co-create knowledge which is useful for the latter. These are only some of the projects which, over the years, have been launched to explore and assess the impact of scientific research. The fact that they were promoted by those who fund research and who are, at least in theory, also its final, direct or indirect, end users, shows the importance of 
the role played by praxis in this issue.

Along a similar vein, it should also be noted that the praxis has fostered studies because of the tendency of national research evaluation agencies to contemplate the impact of research as one of the main criteria for evaluating the quality of academic research (Greco, 2014). In the UK, the Research Excellence Framework (Note 4) (REF) has established that twenty percent of the research assessment activities for the year 2014 had to be based on the impact of research outside of academia, namely on what was defined as: "an effect on, change or benefit to the economy, society, culture, public policy or services, health, the environment or quality of life, beyond academia". Similarly, in the Netherlands, the Standard Evaluation Protocol 2015-2021 (Note 5) establishes that every research unit must draw up a "narrative" which explains the relevance of the research unit's work for society, i.e., its impact in terms of added value for society. This provides strong evidence for the fact that praxis is actively stimulating research on the impact of scientific research and on the way it can be concretely assessed, in an attempt to provide a more comprehensive evaluation of academic results.

Despite all of these efforts, research on the impact of scientific research is still far from achieving a common view of what research impact is and of how it can be assessed. Scholars' views seem to converge towards the idea that impact, interpreted in terms of societal impact, is different from what is called academic impact. In fact, the latter refers to what Gibbons et al. (1994) called Mode 1 research; in this mode, research is supposed to be produced and consumed by academics and, in line with this, its impact can be basically assessed through citations on scientific journals or other bibliometric indexes. In fact, they measure the appreciation or recognition achieved by a research product within the academic arena. On the contrary, societal impact refers to Mode 2 research according to which research is produced for end users which are outside of academia (Bornmann, 2013; Ernø-Kjølhede \& Hansson, 2011). Therefore, it needs to be assessed by adopting different measures which are able to express its usefulness for different stakeholders such as governments, funding institutions, companies, etc. Although the abovementioned distinction seems to be widely acknowledged by scholars in different academic disciplines, there is a considerable degree of differentiation with regard to the way societal impact is interpreted and, consequently, how it is suggested that it should be measured.

A sizeable stream of knowledge has underlined that research impact should be understood as the "consequence of a process in which knowledge and expertise circulates to achieve certain goals that are deemed relevant for the development of society" (Spaapen \& Van Drooge, 2011, p. 212). In this perspective, impact is the effect of what can be called "productive interaction" (de Jong et al., 2014; Molas-Gallart \& Tang, 2011) between stakeholders of research, namely its end users, and researchers, which is instrumental to allow knowledge to circulate and to spread within society. In a similar vein, Watermeyer (2012, p. 120) underlines that: "The impact of academic work may only be judged in terms of its effort to communicate with stakeholders and integrate and inaugurate them as active participants in the research process". In this view, the co-production of knowledge, namely the participation of stakeholders in the research is seen as a way to make the output of a research process impactful (Ozanne \& Saatcioglu, 2008; Ozanne et al., 2017).

This inevitably affects also the way impact is supposed to be measured (Nielsen, 2016). In particular, given the idea that impact results from the establishment of a relationship between researchers and stakeholders, measurement should be focused on the quantity as well as the quality of direct, indirect, and financial relationships established with relevant stakeholders during the research process. Moreover, according to Spaapen and van Drooge (2011, p. 2012): "Research, in order to achieve social impact, has to cross both disciplinary boundaries and those of other professional expertise and of social domains. Therefore, involvement of these domains and their stakeholders in evaluation design and practice is near to a necessity for assessing and achieving social impact". In this view, besides assessing the intensity of the relationships established between researchers and stakeholders, it would also be necessary to get stakeholders involved in the evaluation process. This would ensure a reliable assessment of the impact of scientific research and could lead academics to seriously take into consideration the practical implications of their studies, given that they will be evaluated by those who are the end users of their research (Samuel \& Derrick, 2015).

Other studies have interpreted the impact of scientific research as the effect of a communicative process aimed to favour the diffusion of the research outputs outside the boundaries of academia. According to Bornmann and Marx (2014, p. 2013): "Societal impact is given when the content of a report is addressed outside of science". In this perspective, what makes research impactful is not, or at least not only, the way it is carried out. Rather, it is the fact that, through different meanings, its products are pushed outside of the academic arena in an attempt to reach society. This way of interpreting the impact of research has opened a very prolific avenue of research focused on so-called altmetrics, i.e., alternative metrics (Barbaro, Gentili, \& Rebuffi, 2014; Barnes, 2015; Bornmann, 2015a, 2015b; Bornmann, Haunschild, \& Marx, 2016; Hammarfelt, 2014). According to Shema, 
Bar-Ilan and Thelwall (2014, p. 19), they refer to: "web-based metrics for the impact of scholarly material, with an emphasis on social media outlets as sources of data". In other words, altmetrics allow an assessment of the impact of scientific research which is based on the number of views, downloads, clicks, tweets, likes, etc. that a research output has received. In this perspective, the degree of impact of a research product depends on its level of diffusion outside of academia. It should be noted that some scholars have underscored the limitations of using altmetrics to assess the impact of scientific research (Gumpenberger, Glänzel, \& Gorraiz, 2016). In particular, according to Barnes (2015, p. 128): "It is likely therefore that altmetrics measure not the impact of research, but its consumption". Moreover, Bornmann (2014) is critical as concerns data quality and possible manipulation of data, which are only two examples of factors which could hinder the adoption of altmetrics in an effort to ensure a reliable assessment of the impact of scientific research. These reservations notwithstanding, altmetrics are gaining high consideration within academia. Moreover, their increasing use in assessing the impact of scientific research is demonstrated by the fact that a growing number of academic journals are showing both the altmetric score and the number of citations, or other bibliometric indicators, for every publication.

Finally, another research stream has adopted a very broad view of impact. This is the case in those studies that have interpreted impact as the outcome of the research process. According to Donovan (2008, p. 48): "Research impact denotes the benefits or returns from research, which flow beyond the academic realm to 'end users' of research. These end users are traditionally defined as industry, business, government, or more broadly, the taxpayer". Similarly, Bornmann (2012, p. 673) underlines that: "Societal impact of research concerns the social, cultural, environmental and economic returns from publicly-funded research, be they products or ideas". What has been stated above with regard to the REF is aligned with this view of impact, one which is closely intertwined with the final effects that can result from the use of research outputs. Although this way of interpreting research impact can be considered closest to the abovementioned Mode 2 research, it should also be underlined that adopting this view of impact makes its assessment more complex. According to Martin (2007), criticisms primarily concern the feasibility of linking a given macro effect to a specific research output and, in particular, of doing it in a reliable way. Moreover, there is also an evaluation timescale problem related to the fact that it is not clear when the impact of research manifests itself; this can seriously compromise the assessment process because determining when it should actually start is no simple matter. According to Penfield et al. (2014) criticisms are also related to the fact that this view of impact is not static and, consequently, the moment in which the assessment takes place can influence the degree of reliability of the measurement process leading to over- or under-estimating the actual impact of a given research study. This explains why there are quite diverse methods promoted and adopted to assess the impact of research in different disciplines. In some, like the medical sciences, qualitative and quantitative methods have been suggested to ensure a reliable assessment of the effects that research can have from a social standpoint (Buxton \& Hanney, 1994, 1996, 1998; Hanney, Watt, Jones, \& Metcalf, 2013; Murphy \& Topel, 2003). This variety of contributions can be largely attributed to the fact that, in these disciplines, societal outcomes can be easily determined and their assessment can consequently be focused on specific and clearly determined dimensions. On the contrary, in other disciplines, like management accounting where the link with societal issues is not so strict and measurement is more complex, the path towards attaining a reliable assessment is still long.

\section{A Review of Studies on the Impact of Management Accounting Research}

The debate surrounding the relevance of management accounting research finds its roots in the seminal work of Johnson and Kaplan "Relevance Lost: the Rise and Fall of Management Accounting" (1987) in which the authors underlined the obsolescence of management accounting practices that focused on the use of financial information to control production processes and so, were basically unable to support the changing managerial decision-making processes. Starting from that contribution, other scholars have highlighted the gap between academic research and practice and, in particular, they have raised questions concerning its causes (Modell, 2014; Scapens, 1994; Tucker \& Parker, 2014). In so doing, they have acknowledged that research in the field of accounting and management accounting is gradually losing its societal relevance and, at the same time, they have advocated the need to put in place strategies aimed to overcome this tendency.

It should be argued that the determination of an actual loss of relevance, e.g. of impact, of management accounting research is not deeply debated among scholars. Rather, there seems to be a widespread and general acknowledgment that this process is evident and is on-going. Only a few contributions have explored the actual existence of a gap between theory and practice, even from an empirical standpoint. Tucker and Parker (2014), for instance, have carried out quantitative analyses to prove that academics in the field of management accounting perceive that their studies are gradually losing relevance. Nevertheless, as they underline, their research is focused on senior academics. Therefore, it does not consider the practitioners' view which would be fundamental 
to prove that a real gap between theory and practice exists. The practitioners' perspective has been adopted by Tucker and Schaltegger (2016) who, in their study, contrast the perceptions of representatives of Australian and German professional accounting bodies concerning the gap between theory and practice. The authors show that relevance of topics and communicational problems represent two of the most significant barriers diminishing the impact of management accounting research. Van Helden and Northcott (2010) explore the practical relevance of public sector management accounting research by analysing research published in international accounting journals to ascertain whether their aims are oriented towards informing practice. Basically, their findings support the idea that the degree of orientation towards practical issues is very limited and, even when practical implications are identified and communicated, this does not lead to the provision of specific guidelines useful to practitioners.

Most of the extant literature has focused attention on factors which determine the loss of relevance of management accounting research. Among them, the inconsistency of the object of research is advocated as one of the most influential. According to Shapiro, Kirkman and Courtney (2007), management accounting researchers seem to get lost before translation. In other words, they fail to explore phenomena which are of interest to practitioners. Many scholars share this opinion. Drawing from the works of Ahrens and Chapman (2007) and Seal (2012), Modell (2014) underlines the tendency of management accounting researchers to focus on developing complex theoretical contributions rather than exploring practical and technical issues that would be useful to practitioners. Similarly, Mitchell (2002) states that management accounting research lacks technical richness because of the excessive relevance attributed by scholars to its social dimension. Interestingly, Malmi and Granlund (2009) underline that this focus on social aspects related to management accounting systems is the consequence of the inclination to interpret the pre-adopted theories, rather than the accounting phenomena, as a basis for determining what could be of interest and, consequently, what should drive a research. This is in line with Hopwood (2008, p. 88) who points out that "Often method-led and seemingly subject to waves of fashion, the dynamics behind the development of the accounting research agenda appear to be internal to the academic community itself rather than being influenced by the shifting concerns of practitioners, regulators or even the public at large". In essence, starting from the assumption that the impact of management accounting research depends on its ability to be related to what managers do (Jönsson, 1998), and consequently to what they perceive as useful, it could be argued that one of the major causes underlying loss of relevance lies in the inability to define research questions which are in line with what practitioners expect from research. According to Baldvinsdottir et al. (2010) this is even more surprising, and paradoxical, if we look at the intensification of studies which, in recent times, have adopted empiricism to explore phenomena in the field of management accounting.

Besides being lost before translation, management accounting research has underscored that the causes underlying its loss of relevance can also be found in the researchers' inability to adequately communicate to practitioners, namely in the fact that they also are lost in translation (Shapiro et al., 2007). According to Tucker and Parker (2014) this phenomenon takes place every time researchers fail to present their findings in a way that is understandable for practitioners or when they do not make their contributions available to them through appropriate means. As a matter of fact, Inanga and Schneider (2005) claim that the communication problem arises even before the writing of a paper for a journal. More specifically, they underline that the lack of communication among academics and between academics and practitioners is a barrier to the production of relevant, i.e., impactful, research. Despite acknowledging that a communication problem exists, researchers seem unable to make their research findings interesting for practitioners or to communicate with them (Bromwich and Scapens, 2016). In some cases, this is due to practitioners' unfamiliarity with quantitative and statistical methods, for example, which are often used to analyse and interpret phenomena in the field of accounting and management accounting (Chalmers \& Wright, 2011). Moreover, the fact that management accounting research has become ever more interpretative, rather than normative, has made it less understandable by practitioners who often have a technical, or practical, education (ter Bogt \& van Helden, 2012; Tucker \& Schaltegger 2016). According to Mitchell (2002, p. 282), these changes which occurred with regard to management accounting research has created "semantic and syntactical barriers" between researchers and practitioners, given that the latter often do not have an adequate background to fully understand and appreciate the contribution, especially the theoretical one, given by a research study. That a communicational gap exists is implicitly emphasised also by Hopwood (2008) who suggests that researchers develop marketing and communicational skills in order to effectively be connected with the world of practice. It should also be noted that researchers are often lost in translation (Shapiro et al., 2007) because they are forced by journals to adopt a lexicon which, according to Chapman and Kern (2012), "frequently goes alongside theorizing". These authors also suggest that targeting specific journals for practitioners would help to increase the relevance of management accounting research since, 
in this case, researchers would be asked to adopt vocabulary which is more in line with the expectations as well as the background of professionals.

Literature has also emphasised that the loss of relevance of studies can be traced back to the limited cooperation between academics and practitioners in the field of management accounting. Cooperation goes beyond mere communication as it entails the establishment of a relationship aimed to collect, discuss, and interpret data during the whole research process. Literature has underlined that the absence of practitioners' involvement in the research process would limit the practical relevance of management accounting research. In particular, Mitchell (2002, p. 286) clearly states that: "Academics can improve the attractiveness of their research for practitioners by working more closely with them throughout the research process. The practitioner can become an integral partner in research work and can therefore help in focusing it on issues of practical importance". This does not mean that researchers must lose their roles as independent and critical subjects within the research process (Parker, Guthrie, \& Linacre, 2011). Rather, they should start to dialogue with practitioners but also with industry and regulatory authorities to produce relevant research outputs (Hopwood, 2007, 2008), being careful to not fall in what Al-Htaybat and von Alberti-Alhtaybat (2013) call the "consultancy trap" (p. 21). Although the lack of a strong cooperation between researchers and practitioners can be understood as one of the causes of the loss of relevance of management accounting research, literature has also emphasised that this idea of co-production of knowledge is difficult to apply in practice because of the abovementioned communicative gap. In fact, given that practitioners and academics speak different languages and the former are not used to adopting tools, methods, and techniques which are necessary to carry out academic research in the field of management accounting (Chalmers and Wright, 2011), an ongoing cooperation could be problematic.

Causes behind the loss of relevance of management accounting research also concern the way research is carried out, namely the methodological approaches and methods which are used to explore management accounting systems and their implications. Going back to the 1980s, management accounting research acknowledged that the gap between theory and practice needed to be filled by exploring management accounting practices and how they work within organisations (Scapens, 2006). In this perspective, the inability of management accounting research to be relevant was mainly attributed to the tendency to elaborate complex mathematical models aimed to explain differences among management accounting practices (Scapens, 2006) rather than studying it in the context in which it operated (Flamholtz, 1983; Hopwood, 1983; Laughlin, 1988). To face this situation, in the 1990s qualitative methods started to attract growing attention. In particular, case studies showed their full potential to ensure an in-depth analysis and comprehension of management accounting practices and of their implications (Parker, 2012). The diffusion of case studies should have represented a means of making management accounting research more relevant since they ensure the analysis of reality as well as the understanding of the "antecedents and consequences of managerial accounting practices" (Ittner \& Larcker, 2002, p. 789; Bromwich \& Scapens, 2016). In this perspective, they should have contributed to filling the gap between theory and practice, thus making management accounting research more relevant for practitioners. This has been even more emphasised by the notable diffusion of interventionist studies in the most recent decade (Chiucchi, 2013; Dumay, 2010; Gatti, 2013, 2015; Giuliani \& Marasca, 2011; Jönsson \& Lukka, 2007; Suomala \& Lyly-Yrjänäinen, 2010) in which researchers are called to find a solution to a given (e.g. practical) problem and, at the same time, to provide a theoretical contribution. Through interventionist case studies, scholars have tried to demonstrate how empiricism can contribute to generate relevant and impactful research (Lukka \& Suomala, 2014). Despite this growing adoption of the non-interventionist and interventionist case study method, management accounting research seems to fall short of becoming truly relevant and impactful for society (Baldvinsdottir et al., 2010). The reasons can be found in what Baldvinsdottir et al. (2010, p. 80) call the shift "from a predominant focus on the technical to a predominant focus on the social", which manifests itself in the adoption of complex sociological frameworks to analyse empirical material. Therefore, this means that management accounting research is far from being focused on technical practicalities (Mitchell, 2002; Modell, 2014) and from the language spoken by those who should be its consumers, even when it is based on the adoption of methods - like the case study method - which are so very close intertwined with reality.

Finally, it must also be noted how the literature has brought to light the loss of relevance of management accounting research due to exogenous variables, such as systems adopted by governments to assess the quality of research carried out by universities and research centres. In their work, ter Bogt and Scapens (2012) show how the adoption of new measurement systems more oriented towards quantitative approaches can affect universities' performance. The authors carried out an analysis of the performance measurement systems adopted in the Accounting and Finance groups of the University of Groningen (Netherlands) and of the University of Manchester (UK). Empirical evidence shows that the adoption of quantitative systems generates anxiety and 
uncertainty among researchers. Moreover, the findings also showed a correlation between the use of journal rankings, which is normally associated with the adoption of quantitative systems, and scholars publishing their work in only a limited number of mainstream journals; this, in turn, limits the contribution that their research can give to society (ter Bogt \& Scapens, 2012). This is in line with Chalmers and Wright (2011) who point out that reward and evaluation systems do not encourage the communication between academics and practitioners because they push researchers to publish in peer-reviewed journals which are read only by academics. In other words, given that careers and resources allocated to universities are strictly dependent on the quantity and "academic" quality of research products, researchers are pressured to increase their productivity and to publish their papers in academic journals that can enhance their career, but these works are not able to attract the attention of practitioners. Something similar is stated by Mitchell (2002) who underlines that researchers are constantly under pressure, feeling that they must publish in order to develop a research reputation. To achieve this, they are more oriented towards publishing for other academics, namely in academic journals, since this is the most immediate way to obtain academic recognition and, consequently, to have an academic career. In a similar vein, Hopwood (2008) has also underlined that the quest for an academic career generates internal pressure on researchers who try to increase the number of articles they publish; this often reduces the quality, and consequently the impact, that they can have on society (Gendron, 2008; ter Bogt \& van Helden, 2012).

To sum up, in the field of management accounting the literature has focused particular attention on what seems to have contributed to generating a gap between theory and practice, namely on those factors which have affected the impact of management accounting research by limiting it. This research has been pivotal in offering strategies aimed to eliminate those barriers which would prevent management accounting research from becoming more impactful (Bromwich \& Scapens, 2016; Hopwood, 2008; Mitchell, 2002). Despite this, some new avenues of research can be identified in light of what management accounting research has already highlighted and of what has been accomplished by researchers in other disciplines.

\section{The Impact of Management Accounting Research: An Agenda}

The literature review presented here has shown that both the advent of a gap between theory and practice and the fact that it is the main cause of the loss of relevance of management accounting research are widely acknowledged by researchers. In addition, the extant literature has shed light on and deeply analysed the causes which may have generated the abovementioned gap, showing that they can be traced back to different variables that range from the way researchers write their papers and select topics to external pressures which come from governments and evaluation agencies. Moreover, there appears to be a taken-for-granted assumption of the existence of a gap, and the literature has analysed its determinants in an attempt to find and put forward some possible solutions. Actually, what seems to be lacking and should be the object of future studies is what comes before and after the acknowledgement of the existence of a gap between theory and practice and of the consequent loss of relevance which results from it.

Much research is needed to clearly define what constitutes "impact" in the field of management accounting. As previously stated, while scholars have spotlighted the loss of relevance, or impact, of management accounting research, they have not provided a clear picture of how impact should be understood in the field of management accounting research. This could be interpreted as a redundant question. Actually, it has relevant implications. First, from a theoretical and a practical standpoint, the contribution that management accounting research can give to society can strengthen its perceived relevance both within and beyond the academic arena. Literature has emphasised that disciplines in the field of the Social Sciences and Humanities are less prone to be considered "relevant" or "impactful" because their contribution to society is not "tangible" or "immediate" (Bastow, Dunleavy, \& Tinkler, 2014). For this reason, enhancing the theoretical and empirical debate on the way the "impact" of management accounting research should and could be understood, interpreted, and operationalised can be of utmost importance in order to diffuse the idea that management accounting research can actually be useful to society. In other words, it could contribute to a reconsideration of the role that management accounting research can play in generating public value. Second, shedding light on the nature of the impact of management accounting research can be important to promote its assessment, as it will be discussed later. The lack of contributions on the nature of the impact of management accounting research makes the identification of indicators aimed to assess it more complex because there is no clear idea of the main dimensions in which the impact of management accounting research can be defined. This can partially explain the reasons why, until now, heavy emphasis has been placed on the antecedents, i.e., the determinants, of the loss of impact, while scarce attention has been paid to its assessment. In light of all the above, a relevant avenue of research should entail a deep and epistemological analysis of the multifaceted nature of the impact of management accounting research and of the different ways in which it can be operationalised. 
In carrying out research on what constitutes "impact" in the field of management accounting, the practitioners/professionals' standpoint merits priority consideration. This is beginning to be evident in academic literature as recent studies have highlighted how practitioners who have taken part in REF have been the object of analysis to understand their expectations as well as the criteria they have adopted to assess the impact of research (Derrick \& Samuel, 2016). In this perspective, comparative studies between what constitutes impact for academics and for practitioners should be stimulated not only to allow differences to emerge, but also to provide useful insights for those studies which will try to define how "impact" should be understood in the field of management accounting. Shifting from the perspective of academics to that of practitioners would also facilitate efforts to analyse - from an empirical standpoint - the causes underlying the gap between theory and practice. In other words, it could be important to contribute empirically to the existing literature on the causes underlying the loss of relevance of management accounting research, showing which factors, among those identified by the literature, have a stronger influence and identifying new ones which could be the object of future analysis.

Another interesting avenue of research concerns the analysis of the effects that the co-production of knowledge can have on the impact of management accounting research. Drawing on the literature on "productive interactions" (de Jong et al., 2014; Molas-Gallart \& Tang, 2011; Spaapen \& van Drooge, 2011), impact can be achieved if the knowledge production process is based on the interaction between academics and practitioners. Although the literature in the field of management accounting has emphasised that practitioners should be taken into consideration as the main addressees of research and that this could influence the nature of the issues which are analysed by management accounting research (Hopwood, 2008; Jönsson, 1998; Mitchell, 2002), there is a lack of research on the consequences which can derive thereof, in terms of impact, if research is carried out through what literature calls direct, indirect, or financial interactions between academics and society. In this view, society is not seen as the mere addressee of research but as one of the main actors which takes part in the knowledge creation process. Exploring how the different kinds of productive interactions can influence the impact of management accounting research can be useful not only from an academic perspective but also from a practical standpoint. In fact, it could foster the adoption of those interactive practices which have proven to be able to enhance the impact of management accounting research. Moreover, comparative analysis should be carried out to ascertain whether studies which have adopted a co-operative approach to research are actually perceived as more useful by practitioners, that is to say, if they are understood as more impactful by the end users.

Future analysis should also focus on the assessment of the impact of management accounting research. Although the loss of relevance has been widely debated, literature has primarily focused attention on its causes, up to now. In other words, while the antecedents of the loss of relevance have been questioned and possible solutions have been suggested, there is a lack of studies on the assessment of the impact of management accounting research. This is different from what happens in other fields where there is significant pressure to measure the actual impact of scientific research or to assess progress to that end. The literature has deeply emphasised that the impact of Social Sciences and Humanities research is difficult to assess (Bastow et al., 2014). Despite this, something more should be done to identify indicators and to apply them in the context of management accounting research. This would be useful not only to prove that the abovementioned loss of relevance is not a mere perception but also to shed light on the actual magnitude of the gap between theory and practice in the field of management accounting. There would be noteworthy practical implications as well, because an accurate assessment of the impact of management accounting research should drive the identification of suitable solutions aimed at making studies more relevant and, consequently, at bridging the gap between theory and practice.

Finally, drawing on the literature which has already adopted so-called altmetrics to assess the impact of scientific research (Bornmann, 2014, 2015a, 2015b; Gumpenberger et al., 2016; Hammarfelt, 2014), future studies could try to extend their adoption in the field of management accounting. This would be useful to assess the extent to which management accounting studies are diffused outside of academia and to approximate their ability to influence society. Moreover, this could represent a starting point for carrying out new research focused on the comparison between indicators used to assess the diffusion of research within the boundaries of academia, like bibliometric indicators, and those adopted to measure its influence beyond academia, like altmetrics. This has already been done in other fields of research but the results do not seem to be completely convergent. Carrying out the abovementioned analysis in the field of management accounting research could be important to show the extent to which academic and social relevance are aligned and, in particular, whether the achievement of a high level of relevance from an academic standpoint can strengthen the diffusion of a research product outside of academic boundaries and vice versa. 


\section{Conclusion}

This paper has delved into the impact of management accounting research. This is an issue which had begun to be perceived as pivotal, already in the 1980s, because of the awareness that a disconnect between theory and practice was going to emerge (Flamholtz, 1983; Johnson \& Kaplan, 1987; Scapens, 1994). Although management accounting literature has paid growing attention to this issue, it must be underscored that the analysis has mainly focused on the causes which are at the basis of the loss of relevance. In line with this, removing these causes or trying to limit their negative effects has often been seen as a way to increase the impact of management accounting research. Despite this, only limited progress have been made towards providing a clear definition of what "impact" means in the field of management accounting, what dimensions constitute it, what means or strategies could be adopted to increase it, how it can be assessed, and what relationships can be found between the social and the academic impact. These represent new and highly relevant avenues of research which should be explored to enhance knowledge on the impact of management accounting research and to contribute to filling the abovementioned gap. Moreover, shedding light on the issues would not only further the advancement of knowledge on the impact of management accounting research but would also foster an alignment with other disciplines, especially those, like medicine or engineering, in which the assessment of the impact of scientific research has become both a relevant issue from a theoretical standpoint and a useful tool in practice.

In light of all the above, this paper contributes to the body of literature in two different perspectives. On one side, it systematises a stream of research which has grown significantly in recent years. Contributions have been analysed in order to provide a full comprehension of the state-of-the-art with regard to the impact of management accounting research, shedding light on those main issues which, according to the literature, seem to have hindered the impact of management accounting research. On the other side, the paper has tried to stimulate new reflections which could be useful to advance knowledge and to shift attention from the analysis of the causes of the loss of relevance to its meaning and, in particular, its assessment. From a practical perspective, the paper has identified new avenues of research which could be useful to support both funding and research evaluation agencies which need new and reliable methods for assessing the impact of scientific research in the field of management accounting. In fact, by stimulating research on the design of indicators able to assess the impact of management accounting research, the paper aims to lead scholars to develop and test methods which can take into consideration the complex and multifaceted nature of the impact of research in the field of management accounting.

\section{References}

Ahrens, T., \& Chapman, C. S. (2007). Management accounting as practice. Accounting, Organizations and Society, 32(1), 1-27. https://doi.org/10.1016/j.aos.2006.09.013

Al-Htaybat, K., \& Von Alberti-Alhtaybat, L. (2013). Management accounting theory revisited: seeking to increase research relevance. International Journal of Business and Management, 8(18), 12-24. http://dx.doi.org/10.5539/ijbm.v8n18p12

Baldvinsdottir, G., Mitchell, F., \& Nørreklit, H. (2010). Issues in the relationship between theory and practice in management accounting. Management Accounting Research, 21(2), 79-82. https://doi.org/10.1016/j.mar.2010.02.006

Banzi, R., Moja, L., Pistotti, V., Facchini, A., \& Liberati, A. (2011). Conceptual frameworks and empirical approaches used to assess the impact of health research: An overview of reviews. Health Research Policy and Systems, 9, 1-26. https://doi.org/10.1186/1478-4505-9-26

Barbaro, A., Gentili, D., \& Rebuffi, C. (2014). Altmetrics as new indicators of scientific impact. Journal of the European Association for Health Information and Libraries, 10(1), 3-6. http://hdl.handle.net/10760/24162

Barnes, C. (2015). The use of Altmetrics as a tool for measuring research impact. Australian Academic and Research Libraries, 46(2), 121-134. https://doi.org/10.1080/00048623.2014.1003174

Bastow, S., Dunleavy, P., \& Tinkler J. (2014). The impact of the Social Sciences. How academics and their research make a difference. London: Sage.

Bornmann, L. (2012). Measuring the societal impact of research. EMBO Reports, 13(8), 673-676. https://doi.org/10.1038/embor.2012.99

Bornmann, L. (2013). What is societal impact of research and how can it be assessed? A literature survey. Journal of the American Society for Information Science and Technology, 64(2), 217-233. 
https://doi.org/10.1002/asi.22803

Bornmann, L. (2014). Do altmetrics point to the broader impact of research? An overview of benefits and disadvantages of altmetrics. Journal of Infometrics, 8, 895-903. https://doi.org/10.1016/j.joi.2014.09.005

Bornmann, L. (2015a). Alternative metrics in scientometrics: A meta-analysis of research into three altmetrics. Scientometrics, 103(3), 1123-1144. https://doi.org/10.1007/s11192-015-1565-y

Bornmann, L. (2015b). Usefulness of altmetrics for measuring the broader impact of research: A case study using data from PLOS and F1000Prime. Aslib Journal of Information Management, 67(3), 305-319. https://doi.org/10.1108/AJIM-09-2014-0115

Bornmann, L., Haunschild, R. \& Marx, W. (2016). Policy documents as sources for measuring societal impact: how often is climate change research mentioned in policy-related documents? Scientometrics, 109(3), 1477-1495. https://doi.org/10.1007/s11192-016-2115-y

Bornmann, L., \& Marx, W. (2014). How should the societal impact of research be generated and measured? A proposal for a simple and practicable approach to allow interdisciplinary comparisons. Scientometrics, 98(1), 211-219. https://doi.org/10.1007/s11192-013-1020-x

Bromwich, M., \& Scapens, R. W. (2016). Management Accounting Research: 25 years on. Management Accounting Research, 31, 1-9. https://doi.org/10.1016/j.mar.2016.03.002

Buxton, M., \& Hanney, S. (1994). Assessing payback from Department of Health Research and Development: preliminary report. Brunel University: HERG Research Report.

Buxton, M., \& Hanney, S. (1996). How can payback from health services research be assessed? Journal of Health Services Research, 1(1), 35-43. https://doi.org/10.1177/135581969600100107

Buxton, M., \& Hanney, S. (1998). Evaluating the NHS research and development programme: Will the programme give value for money? Journal of the Royal Society of Medicine, 91(35), 2-6.

Chalmers, K., \& Wright, S. (2011). Bridging accounting research and practice: A value adding endeavor. In E. Evans, R. Burritt \& J. Guthrie (Eds.), Bridging the Gap between Academic Accounting Research and Professional Practice (pp. 59-68). Sydney: The Institute of Chartered Accountants in Australia.

Chapman, C. S., \& Kern, A. (2012). What do academics do? Understanding the practical relevance of research. Qualitative Research in Accounting \& Management, 9(3). https://doi.org/10.1108/qram.2012.31409caa.004

Chiucchi, M. S. (2013). Intellectual capital accounting in action: enhancing learning through interventionist research. Journal of Intellectual Capital, 14(1), 48-68. https://doi.org/10.1108/14691931311289011

De Jong, S., Barker, K., Cox, D., Sveinsdottir, T., \& Van den Besselaar, P. (2014) Understanding societal impact through productive interactions: ICT research as a case. Research Evaluation, 23(2), 1-14. https://doi.org/10.1093/reseval/rvu001

Derrick, G. E., \& Samuel G. N. (2016). The evaluation scale: exploring decisions about societal impact in peer review panels. Minerva, 54(1), 75-97. https://doi.org/10.1007/s11024-016-9290-0

Donovan, C. (2008). The Australian Research Quality Framework: A live experiment in capturing the social, economic, environmental, and cultural returns of publicly funded research. New Directions for Evaluation, 118, 47-60. https://doi.org/10.1002/ev.260

Donovan, C. (2011). State of the art in assessing research impact: introduction to a special issue. Research Evaluation, 20(3), 175-179. https://doi.org/10.3152/095820211X13118583635918

Donovan, C., \& Hanney, S. (2011). The 'payback framework' explained. Research Evaluation, 20(3), 181-183. https://doi.org/10.3152/095820211X13118583635756

Dumay, J. C. (2010). A critical reflective discourse of an interventionist research project. Qualitative Research in Accounting \& Management, 7(1), 46-70. https://doi.org/10.1108/11766091011034271

Ernø-Kjølhede, E., \& Hansson, F. (2011). Measuring research performance during a changing relationship between science and society. Research Evaluation, 20(2), 131-143. https://doi.org/10.3152/095820211X12941371876544

Flamholtz, E. G. (1983). Accounting, budgeting and control systems in their organizational context: theoretical and empirical perspectives. Accounting, Organizations and Society, 8(2-3), 153-169. https://doi.org/10.1016/0361-3682(83)90023-5 
Frank, C., \& Nason, E. (2009). Health research: measuring the social, health and economic benefits. Canadian Medical Association Journal, 180(5), 528-534. https://doi.org/10.1503/cmaj.090016

Gatti, M. (2013). Opening the "black box" of strategy: the role of management accounting systems. International Journal of Finance and Accounting, 2(7), 393-399. https://doi.org/10.5923/j.ijfa.20130207.08

Gatti, M. (2015). Exploring the challenges of measuring intangibles: the implementation of a balanced scorecard in an Italian company. International Journal of Management Cases, 17(4), 120-133.

Gendron, Y. (2008). Constituting the academic performer: the spectre of superficiality and stagnation in academia. European Accounting Review, 17(1), 97-127. https://doi.org/10.1080/09638180701705973

Gibbons, M., Limoges, C., Nowotny, H., Schwartzman, S., Scott, P., \& Trow, M. (1994). The new production of knowledge: The dynamics of science and research in contemporary societies. London: Sage.

Giuliani, M., \& Marasca, S. (2011). Construction and valuation of intellectual capital: a case study. Journal of Intellectual Capital, 12(3), 377-391. https://doi.org/10.1108/14691931111154698

Greco, G. (2014). Una comparazione internazionale tra i sistemi di valutazione della ricerca scientifica. Management Control, 1, 87-99. https://doi.org/10.3280/MACO2014-001006

Gumpenberger, C., Glänzel, W., \& Gorraiz, J. (2016). The ecstasy and the agony of the altmetric score. Scientometrics, 108, 977-982. https://doi.org/10.1007/s11192-016-1991-5

Hammarfelt, B. (2014). Using altmetrics for assessing research impact in the humanities. Scientometrics, 101(2), 1419-1430. https://doi.org/10.1007/s11192-014-1261-3

Hanney, S. R., Watt, A., Jones, T. H., \& Metcalf, L. (2013). Conducting retrospective impact analysis to inform a medical research charity's funding strategies: the case of Asthma UK. Allergy, Asthma and Clinical Immunology, 9, 10-17. https://doi.org/10.1186/1710-1492-9-17

Holbrook, J. B. (2010). The use of societal impacts considerations in a grant proposal peer review: a comparison of five models. Technology and Innovation, 12, 213-224. https://doi.org/10.3727/194982410X12895770314078

Holbrook, J. B., \& Frodeman, R. (2011). Peer review and the ex ante assessment of societal impacts. Research Evaluation, 20(3), 239-246. https://doi.org/10.3152/095820211X12941371876788

Hopwood, A. G. (1983). On trying to study accounting in the contexts in which it operates. Accounting, Organizations and Society, 8(2-3), 287-305. https://doi.org/10.1016/0361-3682(83)90035-1

Hopwood, A. G. (2007). Whither accounting research? The Accounting Review, 82(5), 1365-1374. https://doi.org/10.2308/accr.2007.82.5.1365

Hopwood, A. G. (2008). Changing pressures on the research process: on trying to research in an age when curiosity is not enough. European Accounting Review, 17(1), 87-96. https://doi.org/10.1080/09638180701819998

Inanga, E. L., \& Schneider, W. B. (2005). The failure of accounting research to improve accounting practice: a problem of theory and lack of communication. Critical Perspectives on Accounting, 16(3), 227-248. https://doi.org/10.1016/S1045-2354(03)00073-X

Ittner, C., \& Larcker, D. (2002). Empirical managerial accounting research: are we just describing management consulting practice? European Accounting Review, 11(4), 787-794. https://doi.org/10.1080/0963818022000047082

Johnson, T. H., \& Kaplan, R. S. (1987). Relevance lost. The rise and fall of management accounting. Boston: Harvard Business School Press.

Jönsson, S. (1998). Relate management accounting research to managerial work! Accounting, Organizations and Society, 23(4), 411-434. https://doi.org/10.1016/S0361-3682(97)00018-4

Jönsson, S., \& Lukka, K. (2007). There and back again. Doing IVR in management accounting. In C. Chapman C., A. Hopwood, \& M. Shields (Eds), Handbook of Management Accounting Research, vol. 1 (pp. 373-397). Amsterdam: Elsevier.

Kieser, A., \& Leiner, L. (2009). Why the rigour-relevance gap in management research is unbridgeable. Journal of Management Studies, 46(3), 516-533. https://doi.org/10.1111/j.1467-6486.2009.00831.x

Laughlin, R. C. (1988). Accounting in its social context: An analysis of the accounting systems of the Church of 
England. Accounting, Auditing \& Accountability Journal, 19-42. https://doi.org/10.1108/EUM0000000004622

Lukka, K., \& Suomala, P. (2014). Relevant interventionist research: balancing three intellectual virtues. Accounting and Business Research, 44(2), 204-220. https://doi.org/10.1080/00014788.2013.872554

Malmi, T., \& Granlund, M. (2009). In search of management accounting theory. European Accounting Review, 18(3), 597-620. https://doi.org/10.1080/09638180902863779

Martin, B. R. (2007). Assessing the impact of basic research on society and the economy. Paper presented at the Rethinking the impact of basic research on society and the economy, WF-EST International Conference, Vienna.

McCown, R. L. (2001). Learning to bridge the gap between science-based decision support and the practice of farming: evolution in paradigms of model-based research and intervention from design to dialogue. Australian Journal of Agricultural Research, 52(5), 549-572. https://doi.org/10.1071/AR00119

Mitchell, F. (2002). Research and practice in management accounting: improving integration and communication. European Accounting Review, 11(2), 277-289. https://doi.org/10.1080/09638180020017087

Modell, S. (2014). The societal relevance of management accounting: an introduction to the special issue. Accounting and Business Research, 44(2), 83-103. https://doi.org/10.1080/00014788.2014.882741

Molas-Gallart, J., \& Tang, P. (2011). Tracing 'productive interactions' to identify social impacts: an example from the social sciences. Research Evaluation, 20(3), 219-226. https://doi.org/10.3152/095820211X12941371876706

Morton, S. (2015). Progressing research impact assessment: a 'contributions' approach. Research Evaluation, 24(4), 405-419. https://doi.org/10.1093/reseval/rvv016

Mostert, S. P., Ellenbroek, S. P., Meijer, I., van Ark, G., \& Klasen E. C. (2010). Societal output and use of research performed by health research groups. Research Policy and Systems, 8(1), 30-40. https://doi.org/10.1186/1478-4505-8-30

Murphy, K. M., \& Topel, R. H (Eds.). (2003). Measuring the gains from medical research: An economic approach. Chicago: The University of Chicago Press.

Nicolai, A., \& Seidl, D. (2010). That's relevant! Different forms of practical relevance in management science, Organization Studies, 31(9-10), 1257-1285. https://doi.org/10.1177/0170840610374401

Nielsen, C. (2016). Getting value for money from your science park. Public Money \& Management, 36(7), 539-546. https://doi.org/10.1080/09540962.2016.1237165

Ozanne, J. L., Davis, B., Murray, J. B., Grier, S., Benmecheddal, A., Downey, H., Ekpo, A. E., Garnier, M., Hietanen, J., LeGall-Ely, M., Seregina, A., Thomas, K. D., \& Veer, E. (2017) Assessing the societal impact of research: the relational engagement approach. Journal of Public Policy and Marketing, 36(1), 1-14. https://doi.org/10.1509/jppm.14.121

Ozanne, J. L., \& Saatcioglu, B. (2008). Participatory action research. Journal of Consumer Research, 35(3), 423-439. https://doi.org/10.1086/586911

Paolini, A., \& Quagli, A. (2013). Una riflessione sugli strumenti bibliometrici per la valutazione della ricerca e una proposta: il real impact factor. Management Control, 13, 115-128. https://doi.org/10.3280/MACO2013-003007

Parker, L. D. (2012). Qualitative management accounting research: Assessing deliverables and relevance. Critical Perspectives on Accounting, 23(1), 54-70. https://doi.org/10.1016/j.cpa.2011.06.002

Parker, L. D., Guthrie, J., \& Linacre, S. (2011). The relationship between academic accounting research and professional practice. Accounting, Auditing \& Accountability Journal, 24(1), 5-14. https://doi.org/10.1108/09513571111098036

Penfield, T., Baker, M. J., Scoble, R., \& Wykes, M. C. (2014). Assessment, evaluation and definitions of research impact: a review. Research Evaluation, 23(1), 21-32. https://doi.org/10.1093/reseval/rvt021

Quagli, A., Avallone, F., \& Ramassa, P. (2016). The Real Impact Factor and the gap between accounting theory and practice. Financial Reporting, 1, 29-58. https://doi.org/10.3280/FR2016-001003

Reale, E., Nedeva, M., Duncan, T., \& Primeri, E. (2014). Evaluation through impact: a different viewpoint. Fteval Journal for Research and Technology Policy Evaluation, 39, 36-40. 
Samuel, G. N., \& Derrick G. E. (2015). Societal impact evaluation: Exploring evaluator perceptions of the characterization of impact under the REF2014. Research Evaluation, 24(3), 229-241. https://doi.org/10.1093/reseval/rvv007

Scapens, R. W. (1994). Never mind the gap: towards an institutional perspective on management accounting practice. Management Accounting Research, 5(3-4), 301-321. https://doi.org/10.1006/mare.1994.1019

Scapens, R. W. (2006). Understanding management accounting practices: A personal journey. The British Accounting Review, 38(1), 1-30. https://doi.org/10.1016/j.bar.2005.10.002

Seal, W. (2012). Some proposals for impactful management control research. Qualitative Research in Accounting \& Management, 9(3), 228-244. https://doi.org/10.1108/11766091211257461

Shapiro, D. L., Kirkman, B. L., \& Courtney H. G. (2007). Perceived causes and solutions of the translation problem in management research. Academy of Management Journal, 50(2), 249-266. https://doi.org/ 10.5465/AMJ.2007.24634433

Shema, H., Bar-Ilan, J., \& Thelwall, M. (2014). Do blog citations correlate with a higher number of future citations? Research blogs as a potential source for alternative metrics. Journal of the Association for Information Science and Technology, 65(5), 1018-1027. https://doi.org/ 10.1002/asi.23037

Spaapen, J., \& van Drooge, L. (2011). Introducing 'productive interactions' in social impact assessment. Research Evaluation, 20(3), 211-218. https://doi.org/10.3152/095820211X12941371876742

Suomala, P., \& Lyly-Yrjänäinen, J. (2010). Interventionist management accounting research: Lessons learned. CIMA, Research Executive Summaries Series, 6(1), 1-9.

Ter Bogt, H. J., \& Scapens, R. W. (2012). Performance management in universities: Effects of the transition to more quantitative measurement systems. European Accounting Review, 21(3), 451-497. https://doi.org/10.1080/09638180.2012.668323

Ter Bogt, H., \& van Helden, J. (2012). The practical relevance of management accounting research and the role of qualitative methods therein: The debate continues. Qualitative Research in Accounting \& Management, 9(3), 265-273. https://doi.org/10.1108/11766091211257470

Tucker, B., \& Parker, L. (2014). In our ivory towers? The research-practice gap in management accounting. Accounting and Business Research, 44(2), 104-143. https://doi.org/10.1080/00014788.2013.798234

Tucker, B. P., \& Schaltegger, S. (2016). Comparing the research-practice gap in management accounting: A view from professional accounting bodies in Australia and Germany. Accounting, Auditing \& Accountability Journal, 29(3), 362-400. https://doi.org/10.1108/AAAJ-02-2014-1601

Upton, D. J. (1999). How can we achieve evidence based practice if we have a theory-practice gap in nursing today? Journal of Advanced Nursing, 29(3), 549-555. https://doi.org/10.1046/j.1365-2648.1999.00922.x

Van Helden, G. J., \& Northcott, D. (2010). Examining the practical relevance of public sector management accounting research. Financial Accountability \& Management, 26(2), 213-240. https://doi.org/ 10.1111/j.1468-0408.2010.00499.x

Wandersman, A., Duffy, J., Flaspohler, P., Noonan, R., Lubell, K., Stillman, L., Blachman, M., Dunville, R., \& Saul, J. (2008). Bridging the gap between prevention research and practice: the interactive systems framework for dissemination and implementation. American Journal of Community Psychology, 41(3-4), 171-181. https://doi.org/10.1007/s10464-008-9174-z

Watermeyer, R. (2012). From engagement to impact? Articulating the public value of academic research. Tertiary Education and Management, 18(2), 115-130. https://doi.org/10.1080/13583883.2011.641578

\section{Notes}

Note 1. http://impact-ev.eu/

Note 2. http://simpatic.eu/

Note 3. http://www.siampi.eu/

Note 4. http://www.ref.ac.uk/

Note 5. https://www.knaw.nl/nl/actueel/publicaties/standard-evaluation-protocol-2015-2021 


\section{Copyrights}

Copyright for this article is retained by the author(s), with first publication rights granted to the journal.

This is an open-access article distributed under the terms and conditions of the Creative Commons Attribution license (http://creativecommons.org/licenses/by/4.0/). 